\title{
Milk fat threshold determination and the effect of milk fat content on consumer preference for fluid milk
}

\author{
K. S. McCarthy, ${ }^{*}$ K. Lopetcharat, $†$ and M. A. Drake ${ }^{* 1}$ \\ *Department of Food, Bioprocessing and Nutrition Sciences, Southeast Dairy Foods Research Center, North Carolina State University, \\ Raleigh 27695 \\ †Nouveau Centric Co. Ltd., Bangkok 10250, Thailand
}

\begin{abstract}
Milk consumption in the United States has been in decline since the 1960s. Milk fat plays a critical role in sensory properties of fluid milk. The first objective of this study was to determine the change in percent milk fat needed to produce a detectable or just noticeable difference (JND) to consumers in skim, 1\%, 2\%, and whole milks. The second objective was to evaluate how milk fat affected consumer preferences for fluid milk. Threshold tests were conducted to determine the JND for each reference milk (skim, $1 \%, 2 \%$, and whole milk), with a minimum of 60 consumers for each JND. The JND was determined for milks by visual appearance without tasting and tasting without visual cues. Serving temperature effect $\left(4,8\right.$, or $\left.15^{\circ} \mathrm{C}\right)$ on tasting JND values were also investigated. The established JND values were then used to conduct ascending forced-choice preference tests with milks. Consumers were assigned to 3 groups based on self-reported milk consumption: skim milk drinkers $(\mathrm{n}=59)$, low-fat milk drinkers (consumed $1 \%$ or $2 \%$ milk, $\mathrm{n}=64$ ), and whole milk drinkers $(\mathrm{n}=49)$. Follow-up interviews were conducted where consumers were asked to taste and explain their preference between milks that showed the most polarization within each consumer segment. Descriptive sensory analysis was performed on the milks used in the follow-up interviews to quantify sensory differences. Visual-only JND were lower than tasting-only JND values. Preference testing revealed 3 distinct preference curves among the consumer segments. Skim milk drinkers preferred skim milk and up to $2 \%$ milk fat, but disliked milk higher in fat due to it being "too thick," "too heavy," "flavor and texture like cream," "too fatty," and "looks like half and half." Low-fat milk drinkers preferred $2 \%$ milk up to $3.25 \%$ (whole milk), but then disliked higher milk fat content. Whole milk drinkers
\end{abstract}

Received May 7, 2016

Accepted November 3, 2016.

${ }^{1}$ Corresponding author: maryanne_drake@ncsu.edu preferred whichever milk was higher in milk fat regardless of how high the fat content was, distinct from skim and low-fat milk drinkers. The findings of this study provide insights on sensory characteristics of milk fat in fluid milk and consumer sensory perception of these properties. These results also provide insights on how the industry might adjust milk fat references for adjusting milk sensory properties to increase milk preference and remain within the standards of identity of milk.

Key words: milk fat, just noticeable difference, milk

\section{INTRODUCTION}

Fluid milk has seen a steady decline in sales over the last several decades whereas other dairy products, such as yogurt and cheese, have increased in per capita consumption in the United States. From 1975 to 1995 to 2014, milk consumption decreased from 112.05 to 93.12 to $71.92 \mathrm{~L}$ (29.6 to 24.6 to 19.0 gallons) per person (Economic Research Service, 2015). Although total consumption has declined, changes in the type of milk most commonly purchased have also been observed. In the 21 yr spanning 1966 to 1987, low-fat milk increased in sales by $30.0 \%$, whereas whole milk sales decreased by $44.8 \%$ (Gould et al., 1990). Sales of $2 \%$ reduced-fat milk alone have outsold whole milk every month since January 2005, whereas skim milk sales have remained relatively stable (Economic Research Service, 2014). Fat contributes a variety of flavors, mouthfeel, and visual attributes to milk. Previous work has confirmed that the desirable flavors in milk come from compounds probably unique to milk fat (Tamsma et al., 1969).

Brewer et al. (1999) surveyed 100 women about milk consumption and milk attitudes, and $82 \%$ selected skim or reduced fat as the milk they most frequently consumed. All consumers in their study were asked questions pertaining to their attitudes and beliefs of various milks. The women, as a whole, including the $82 \%$ who purchased skim or reduced fat milk, actually preferred whole milk, confirming that many desirable sensory aspects of milk were contributed by milk fat. Those authors concluded that health beliefs played a pertinent 
role in decisions for milk purchase (Brewer et al., 1999). More recently, Bakke et al. (2016) also reported that health consciousness had no effect on preferred milk fat levels in blinded tastings of fluid milk.

In addition to contributing to flavor, fat plays a role in the visual attributes of milk. Phillips et al. (1995) used a trained panel to demonstrate that increasing levels of milk fat gave milk a whiter appearance. Increased milk fat also increased perceived thickness, mouth coating, and residual mouth coating by the trained panel (Phillips et al., 1995). Another study evaluated milk appearance and its relationship to perceived thickness by trained panelists (Quiñones et al., 1997). A high correlation was found between instrumental whiteness and trained panel thickness of milk.

Milk fat is associated with the desirable consumer attribute of creaminess. Richardson-Harman et al. (2000) showed that creaminess was defined by highfat dairy products that exhibited dairy flavors such as cream aroma, butter aroma, and vanilla flavor, and texture characteristics of mouth coating, slipperiness, and higher viscosity. Creaminess was positively related to product liking. Tepper and Kuang (1996) evaluated the perception of fat content in skim milk using a select group of milk consumers. Results showed that powdered natural cream flavor and not the addition of vegetable oil provided the sensation of higher fat content in skim milk, suggesting that specific aromatics rather than viscosity were key contributors from milk fat. Jervis et al. (2014) evaluated the effect of different modalities on perceived creaminess and how creaminess affected overall liking in sour cream. In full-fat sour cream, flavor played the biggest role when assessing creaminess. As fat was removed, other modalities of visual appearance, physical stirring, and in-mouth texture played a more important role in fat perception. Those authors also reported that samples scoring high in overall liking were also rated highly in creaminess. These studies collectively demonstrate that both appearance and flavor contribute to creamy perception in dairy products and that creaminess is a desired attribute in dairy products.

Threshold tests are used to determine the lowest concentration for detection of sensory changes. A just noticeable difference (JND) threshold is the minimum change in a stimulus to elicit a detectable difference (Allen, 1981). Drake et al. (2011) determined JND values for sodium chloride in dairy products and proposed that this information could be used to reduce $\mathrm{NaCl}$ without consumers detecting differences. Previous work has established that milk fat content of fluid milk is a critical sensory parameter for appearance, flavor, and mouthfeel, but the role of specific concentrations of milk fat has not been determined. Appearance has been purported to play the primary role in consumer differentiation and selection of fluid milk. Our hypothesis was that sensory factors other than appearance influence consumer perception of milk fat and consumer selection of fluid milk. The objectives of our study were to determine the change in milk fat needed to produce a JND to consumers in skim, $1 \%, 2 \%$, and whole milks. The second objective was to evaluate how milk fat affected consumer preferences for fluid milk.

\section{MATERIALS AND METHODS}

\section{Sample Preparation}

Raw milk was obtained from the North Carolina State University Dairy Enterprise System. A cold bowl separator was used to skim the milk fat and the raw milk was then standardized to $0.1,3.25$, or $42.0 \%$ milk fat. After the fat content of milk was standardized, it was then pasteurized at $72.8^{\circ} \mathrm{C}$ for $25 \mathrm{~s}$ and homogenized at $10,342 \mathrm{kPa}$ for the first stage and $3,447 \mathrm{kPa}$ for the second stage to produce the base milks. Milks were stored in sterile bag and box containers at $4^{\circ} \mathrm{C}$ in the dark. The skim milk, whole milk, and heavy cream were then mixed to desired milk fat concentrations. Mojonnier analysis was conducted in triplicate to confirm milk fat concentrations of base milks and then each test sample (AOAC International, 1992: method number 989.05). Milk was stored with black plastic coverings and was mixed and prepared for sensory testing with overhead lights off to prevent light oxidation.

\section{Threshold Tests}

Threshold testing was conducted to determine the amount of milk fat needed to a produce a JND to consumers for each reference milk (skim, 1\%, 2\%, and $3.25 \%$ ). Milk at $0.1,1,2$, and $3.25 \%$ (whole milk) milk fat served as the respective reference milk for each test. Those milk fats were chosen as they are the standard milks available in the commercial market. Milk fat concentrations for each threshold series were based on preliminary tests. The JND for milk fat of skim, $1 \%, 2 \%$, and whole milk as the reference milks under 2 conditions was determined: tasting without visual cues and visual cues only with no tasting. Threshold tests within each condition were tested in separate sessions a minimum of $7 \mathrm{~d}$ apart. The 4 tasting without visual cues JND tests were conducted first across an 8-wk period. Four weeks later, the visuals cues only tests were conducted. Within each of these conditions, the reference fat content evaluated was in a randomized order. Two weeks later, the effect of serving temperature 
on tasting JND without visual cues was also evaluated at 3 temperatures $\left(4,8\right.$, and $\left.15^{\circ} \mathrm{C}\right)$ for skim milk only. A total of $11 \mathrm{JND}$ thresholds tests (4 visual, 4 tasting JND, and 3 temperature JND tests) were conducted.

Consumers were recruited from the online database maintained by the Sensory Service Center (Raleigh, NC) to participate in threshold tests. A minimum of $\mathrm{n}=60$ milk consumers participated in each JND test. All consumer testing was conducted in accordance with regulations from the North Carolina State University Institutional Review Board for the Protection of $\mathrm{Hu}-$ man Subjects in Research. Compusense Cloud (Guelph, Canada) was used to collected data. Consumers were compensated with a food treat.

For tasting without visual cues, the JND for each reference milk fat was evaluated by a 5 -series, ascending forced choice (AFC) threshold test. Step factors for each threshold test were determined by preliminary tests to select a range within which most consumers would detect differences. A step factor of 2.2 was used for skim milk, a step factor of 1.7 was used for $1 \%$ milk, a step factor of 1.5 was used for $2 \%$, and a step factor of 1.4 was used for whole milk. In testing without visual cues, panelist tasted the milks under red lights and the milk was served in $177-\mathrm{mL}$, white Styrofoam cups to minimize visible differences in the milks. The reference milk was served in 2 of the white Styrofoam cups and a third white Styrofoam cup contained the test sample of the milk with an increased milk fat concentration. Each cup contained $59 \mathrm{~mL}$ of the designated sample and was labeled with a random 3-digit code. Milks were served at $4^{\circ} \mathrm{C}$ except for the tests that evaluated serving temperature effects. For each series, consumers were presented with all 3 samples. They were asked to taste the milks in the order presented on the ballot and to select the one they thought was different. Cups within each series were presented in a randomized order presentation across all panelists. A 4-min wait was imposed between each series to prevent carryover effects. The session was limited to 5 series to prevent fatigue.

When consumers were to only visually evaluate the milks, samples $(59 \mathrm{~mL})$ were served in $177-\mathrm{mL}$ clear plastic tumblers with random 3-digit codes under normal indoor fluorescent lighting conditions. As consumers did not taste samples, an 8-series 3-AFC was used, with all other aspects of preparation and data collection remaining the same as the tasting condition without visual cues testing. Milks were served in clear plastic tumblers during the visual testing to imitate how consumers would normally consume milk. For the visual tests, a step factor of 1.5 was used for skim milk, and a step factor of 1.3 was used for $1 \%, 2 \%$, and whole milk.

\section{Preference Testing}

The calculated JND values from the threshold tests for skim, $1 \%$, and $2 \%$ milk were then used to determine the fat contents used to conduct preference testing to determine how the just noticeable fat difference affected consumer preferences for milks. The whole milk JND values were not used, as they far exceeded any milk that would be commercially available. The milks evaluated included skim milk ( $0.1 \%$ milk fat), $1 \%, 2 \%$, whole milk (3.25\% milk fat), as well as $4.5 \%$ (skim tasting JND), $6.1 \%$ (1\% tasting-only JND), and $6.6 \%$ fat milks ( $2 \%$ tasting-only JND). The tasting-only JND were used as these covered both the visual JND and the tasting JND of each reference milk. Preference tests with all senses engaged were investigated with self-reported consumer groups of skim milk drinkers ( $\mathrm{n}=59$ ), low-fat milk drinkers (defined as those who drank $1 \%$ or $2 \%$ milk; $\mathrm{n}=64$ ), and whole milk drinkers $(\mathrm{n}=49)$. We hypothesized that subtle distinctions in sensory cues from these different segments of consumers might not be fully distinguished in a traditional threshold test with a smaller number of general milk consumers. Consumers were again recruited from the online database maintained by the Sensory Service Center. Milks were prepared in the same manner as for the threshold tests and served $(59 \mathrm{~mL})$ in $177-\mathrm{mL}$ clear plastic tumblers with random 3-digit codes. Consumers tasted all possible combinations of the 7 milks (21 pairs total; Table 1) of the reference and test milks served at $4^{\circ} \mathrm{C}$ (a forced-choice preference, 2-AFC) across 3 separate sessions on 3 separate days. Consumers tasted 7 pairs each day, with a 3-min enforced rest between each pair. Consumers were presented with a random pair of the 7 samples and asked to select which sample of the pair they preferred. Data for all sessions were collected using Compusense Cloud (Guelph, Canada). Preference test participants were compensated with a gift card to a local store.

\section{Preference Follow-Up Interviews}

A subset (minimum of $\mathrm{n}=10$ from each milk fat consumer group) of the consumers who completed the preference testing were asked to participate in follow-up interviews. Milks were prepared in the same manner as for the JND and preference testing. Skim milk consumers were presented with 3 pairs of milk separately and asked to identify which sample of the pair they preferred and why. The 3 pairs that were given were skim versus $2 \%$ milk, $2 \%$ versus whole milk, and skim versus milk standardized to $6.6 \%$ milk fat. Low-fat milk drinkers were presented with 3 pairs as 
Table 1. Sample pairs used for ascending forced-choice preference tests (percentages refer to milk fat content) ${ }^{1}$

\begin{tabular}{lll}
\hline Pair & Sample 1 & Sample 2 \\
\hline 1 & Skim (0.1\%) & $1 \%$ \\
2 & Skim (0.1\%) & $2 \%$ \\
3 & Skim (0.1\%) & Whole milk $(3.25 \%)$ \\
4 & Skim (0.1\%) & $4.5 \%$ \\
5 & Skim (0.1\%) & $6.1 \%$ \\
6 & Skim (0.1\%) & $6.6 \%$ \\
7 & $1 \%$ & $2 \%$ \\
8 & $1 \%$ & Whole milk $(3.25 \%)$ \\
9 & $1 \%$ & $4.5 \%$ \\
10 & $1 \%$ & $6.1 \%$ \\
11 & $1 \%$ & $6.6 \%$ \\
12 & $2 \%$ & Whole milk $(3.25 \%)$ \\
13 & $2 \%$ & $4.5 \%$ \\
14 & $2 \%$ & $6.1 \%$ \\
15 & $2 \%$ & $6.6 \%$ \\
16 & Whole milk $(3.25 \%)$ & $4.5 \%$ \\
17 & Whole milk (3.25\%) & $6.1 \%$ \\
18 & Whole milk (3.25\%) & $6.6 \%$ \\
19 & $4.5 \%$ & $6.1 \%$ \\
20 & $4.5 \%$ & $6.6 \%$ \\
21 & $6.1 \%$ & $6.6 \%$ \\
\hline
\end{tabular}

${ }^{1}$ Pairs and samples within pairs were served in a random presentation.

well, skim versus $2 \%$ milk, $2 \%$ versus whole milk, and $2 \%$ versus $6.6 \%$ fat milk. Whole milk drinkers were presented with 2 pairs, skim versus whole milk and whole versus $6.6 \%$ fat milk. These pairs were chosen for each consumer segment based on the preference test results and the most polarization within each group. Milks were presented in the same format as for consumer testing. Each interview lasted approximately $30 \mathrm{~min}$. The same person conducted all interviews to minimize bias and took notes from each interview. Panelists who completed the interview were compensated with a gift card to a local store.

\section{Descriptive Analysis}

Descriptive analysis was conducted on the same milks used in the follow-up interviews, a subset from the preference test, to document the analytical sensory properties of each milk. The descriptive panel comprised 8 trained panelists (ages 22-45 yr) employed by North Carolina State University. Each panelist had a minimum of $65 \mathrm{~h}$ of prior descriptive analysis training on food flavor and mouthfeel or texture attributes using the Spectrum method (Meilgaard et al., 2007), as well as at least $20 \mathrm{~h}$ of prior experience with the evaluation of sensory properties of fluid milk and milk powders (Drake et al., 2003; Croissant et al., 2007). Milks were evaluated at $10^{\circ} \mathrm{C}$. Milks $(85 \mathrm{~mL})$ were dispensed into coded 118-mL plastic soufflé cups with lids. Sample preparation was conducted with overhead lights off to avoid any light oxidation of the samples.
At the beginning of each evaluation session, panelists were calibrated with 3 commercial warm-up samples of half and half, whole milk, and skim milk that panelists had previously characterized. Panelists expectorated samples and, between samples, rinsed with deionized water and cleansed their palate with unsalted crackers. A 3-min wait time between samples was enforced. The order of presentation of samples was randomized and balanced to account for presentation and carryover effects.

Opacity, color, and viscosity were evaluated in separate sessions from flavor to prevent interactions. For the evaluation of opacity, references of water and whole fat milk were provided to panelists. All samples were served in black 118-mL plastic soufflé cups with lids and random 3-digit codes. Color was evaluated by dispensing approximately $80 \mathrm{~mL}$ of each sample into $100 \times 10 \mathrm{~mm}$ disposable, plastic Petri dishes (Thermo Scientific, Waltham, MA). The Petri dishes were placed on a white paper background and Behr paint chips ("Ultra-Pure White" PPU18-06 = 0.0 and "Glass of Milk" P260-1u = 3.5; Behr, Santa Ana, CA) were used as references for yellow color. Milks were evaluated in triplicate by each panelist with separate sessions for each replication. The sensory lexicon used for milks was adapted from Croissant et al. (2007) (Table 2).

\section{Statistical Analysis}

Statistical analysis was conducted using XLSTAT Version 2013.5.03 (Addinsoft, New York, NY). Thresholds were determined using the approach described by ASTM procedure E679-04 (ASTM, 2011). Individual best-estimated-threshold values for JND concentrations were $\log _{10}$-transformed and submitted to a 1-way ANOVA with concentration as fixed factors. Preference curves were plotted based on the proportion of consumers preferring sample over the reference sample for each consumer group and a binomial test was performed on each proportion at $95 \%$ confidence. Qualitative data from the interviews were tallied for the most common answers among each group. Descriptive analysis data were analyzed by a 2-way ANOVA using panelist and samples as fixed factors with Fisher's least significant difference test for means separation.

\section{RESULTS AND DISCUSSION}

\section{Threshold Tests}

The JND values for visual cues only were lower than the tasting-only JND within each reference milk $(P<$ 0.05 ; Table 3$)$. The skim milk visual JND was $0.4 \%$ 
Table 2. Trained panel sensory attributes for fluid milk

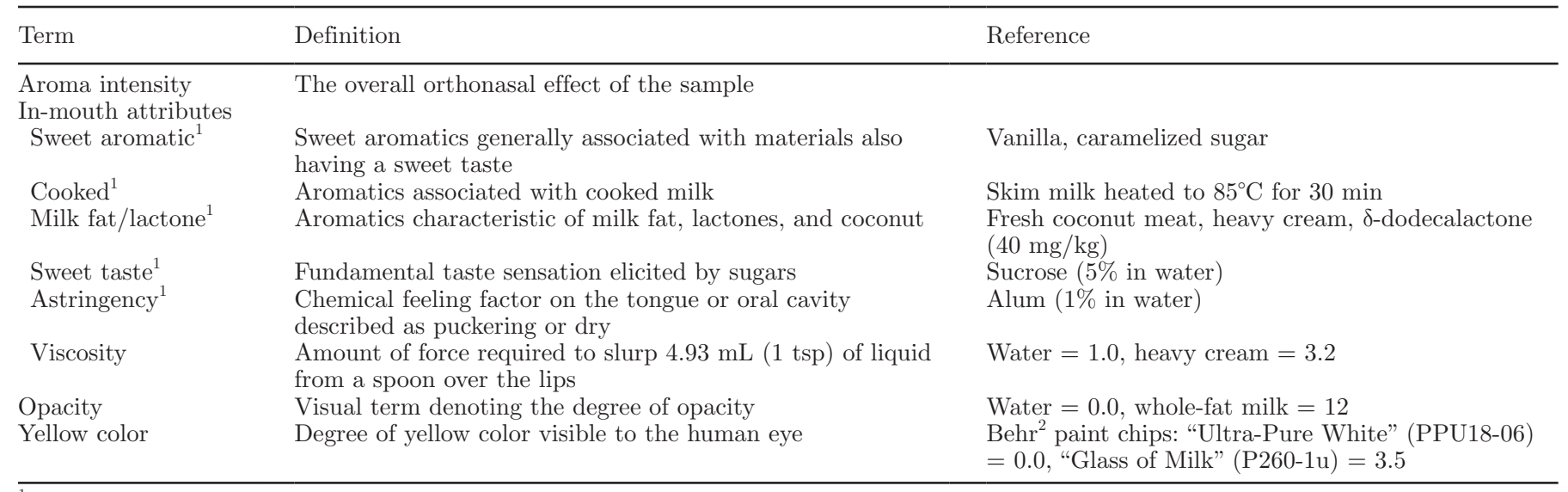

${ }^{1}$ Terms adapted from Croissant et al. (2007).

${ }^{2}$ Behr, Santa Ana, CA.

milk fat whereas the tasting-only JND was $4.4 \%$ milk fat (Table 3).This difference is consistent with results published by Phillips et al. (1995), where a trained panel was not able to distinguish differences in any flavor or aroma attribute between skim and $2 \%$ milk when evaluating the milk under red lights. When the trained panelists evaluated the milks under normal lights, differences were detected between $0.06 \%$ milk and $0.5 \%$ milk in color and opacity. Visual differences are detected at a much smaller change in milk fat than flavor and aroma attributes. It is important to note that as the base milk increased in fat, the JND for visual cues only increased in a similar magnitude (Table 3), which is consistent with expected results. Just noticeable differences are proportional to the magnitude of the starting stimuli (Smeets and Brenner, 2008). The tasting JND also increased with base fat percentage, but not to the same degree as the visual JND (Table 3). No significant difference was found in JND as a function of serving temperature $(P>0.05)$, and therefore only the $4^{\circ} \mathrm{C}$ results are presented. Previous research has also demonstrated that trained panel performance of milk and cheeses in terms of attributes, intensities, or differences between treatments was not affected by serving temperature (Drake et al., 2005; Francis et al., 2005).

\section{Preference Testing}

A total of 172 self-reported milk consumers participated in the milk paired preference tests, $30.2 \%$ males and $69.8 \%$ females, 19 to 35 yr old, and mostly Caucasian $(69.3 \%)$. Overall, when consumers were given skim milk in a pair, the higher-milk fat sample was always preferred $(P<0.05$; Figure 1$)$. More differences in milk fat preference were noted when results were separated by typical milk fat content consumed. When skim milk drinkers were presented with skim milk versus $1 \%$ milk, they preferred $1 \%(P<0.05$; Figure 2$)$ and also preferred $2 \%$ over skim milk $(P<0.05)$. For $3.3,4.5$, and $6.1 \%$ fat content, we found no differences in preference $(P>0.05)$, but when presented with $6.6 \%$ fat milk and skim milk consumers preferred skim milk $(P<0.05$; Figure 2). Low-fat milk drinkers preferred $1 \%, 2 \%$, and whole milk over skim milk $(P<0.05$; Figure 2). When given $1 \%$ versus whole milk, whole milk was preferred $(P<0.05)$. When $\geq 4.5 \%$ fat milk was presented compared with $1 \%$ fat milk, we found no differences in preference $(P>0.05)$. Similar results were obtained from low-fat milk drinkers when $2 \%$ fat milk was the reference (Figure 2).

Whole milk drinkers preferred whole milk over skim or $1 \%$ milk $(P<0.05$; Figure 2$)$, but we observed no difference in their preference between whole milk and $2,4.5,6.1$, or $6.6 \%$ fat milk. Milk with 6.1 or $6.6 \%$

Table 3. The amount of milk fat increase needed to produce a just noticeable difference (JND) in each reference milk for each test condition $^{1}$

\begin{tabular}{lcc}
\hline Reference milks & $\begin{array}{c}\text { Visual } \\
\text { cues } \\
\text { only }\end{array}$ & $\begin{array}{c}\text { Tasting } \\
\text { without } \\
\text { visual }\end{array}$ \\
\hline Skim milk $(0.1 \%)$ & $0.4^{\mathrm{b}, \mathrm{D}}$ & $4.4^{\mathrm{a}, \mathrm{C}}$ \\
$1 \%$ milk & $1.5^{\mathrm{b}, \mathrm{C}}$ & $5.1^{\mathrm{a}, \mathrm{B}}$ \\
$2 \%$ milk & $3.0^{\mathrm{b}, \mathrm{B}}$ & $4.6^{\mathrm{a}, \mathrm{B}}$ \\
Whole milk $(3.25 \%)$ & $4.3^{\mathrm{b}, \mathrm{A}}$ & $6.0^{\mathrm{a}, \mathrm{A}}$ \\
\hline
\end{tabular}

${ }^{\mathrm{A}-\mathrm{D}}$ Uppercase letters represent significant differences within each column $(P<0.05)$.

${ }^{\mathrm{a}, \mathrm{b}}$ Lowercase letters designate differences within rows $(P<0.05)$.

${ }^{1}$ Data represent at minimum $\mathrm{n}=60$ consumers for each JND value. Difference in milk fat is presented and was calculated by the group JND fat $\%$ - reference fat $\%=$ difference in $\%$. Log 10 -transformation of best-estimated thresholds were used in a 1-way ANOVA to determine statistical significance. 
fat were also preferred over skim and $1 \%$ fat milk for this group of consumers $(P<0.05$; results not shown). Whole milk drinkers preferred any fat sample over skim milk, but as the test sample increased in fat content, they preferred the higher fat sample up to whole milk $(P<0.05$; Figure 2). Palacios et al. (2009) observed 2 consumer segments for sensory attributes of cow milk, one segment being cream seekers, who preferred strong milk aroma, creaminess, and smoothness. People who consume whole milk normally can be categorized in that more milk fat is always preferred.

These results show preferences for skim milk drinkers and low-fat milk drinkers for higher fat content milk than is typically consumed, but not an extreme amount beyond what they usually consume. Consumer preference was influenced by milk fat content and which milk fat percentage they were accustomed to in their daily life. Tuorila (1987) reported that skim milk drinkers scored whole milk the lowest in a hedonic liking test, low-fat drinkers scored low-fat and whole milk higher than skim milk, and whole milk drinkers rated whole milk highest in the hedonic test. Bakke et al. (2016) evaluated consumer preferences for milk fat across a smaller range of milk fats $(0.1-3.5 \%)$ without addressing milk fat thresholds and with a small pool of consumers; they also demonstrated that milk fat typi- cally consumed did not necessarily redict preferred milk fat in blind tasting, generally consistent with what we observed. Low-fat milk consumers preferred 1 or $2 \%$ fat milk whereas whole milk consumers preferred whole milk. Skim milk consumers did not show any pointed preferences until whole milk was presented and then preference sharply decreased, again consistent with the results from our study. Perhaps not surprisingly, differences in preferences for milk fat content in milk were lower than the blind tasting JND values, also suggesting the role of visual properties or cues that are specific to specific segments of milk consumers.

Previous research has shown that consumers preferred whole milk in a milk acceptance test (Brewer et al., 1999), and Saba et al. (1998) showed from survey results (no tasting) that consumers preferred the milk that they usually consumed. However, Brewer et al. (1999) did not evaluate liking scores segmented by milk type consumed and Saba et al. (1998) grouped those who drank skim milk up to $2 \%$ in one segment. Bakke et al. (2016) also noted that averaging across all milk consumers without segmenting for milk fat typically consumed masked specific milk fat preferences within each consumer group, although they could only make limited conclusions about whole milk consumers due to a small population $(\mathrm{n}=15)$ and they did not evaluate

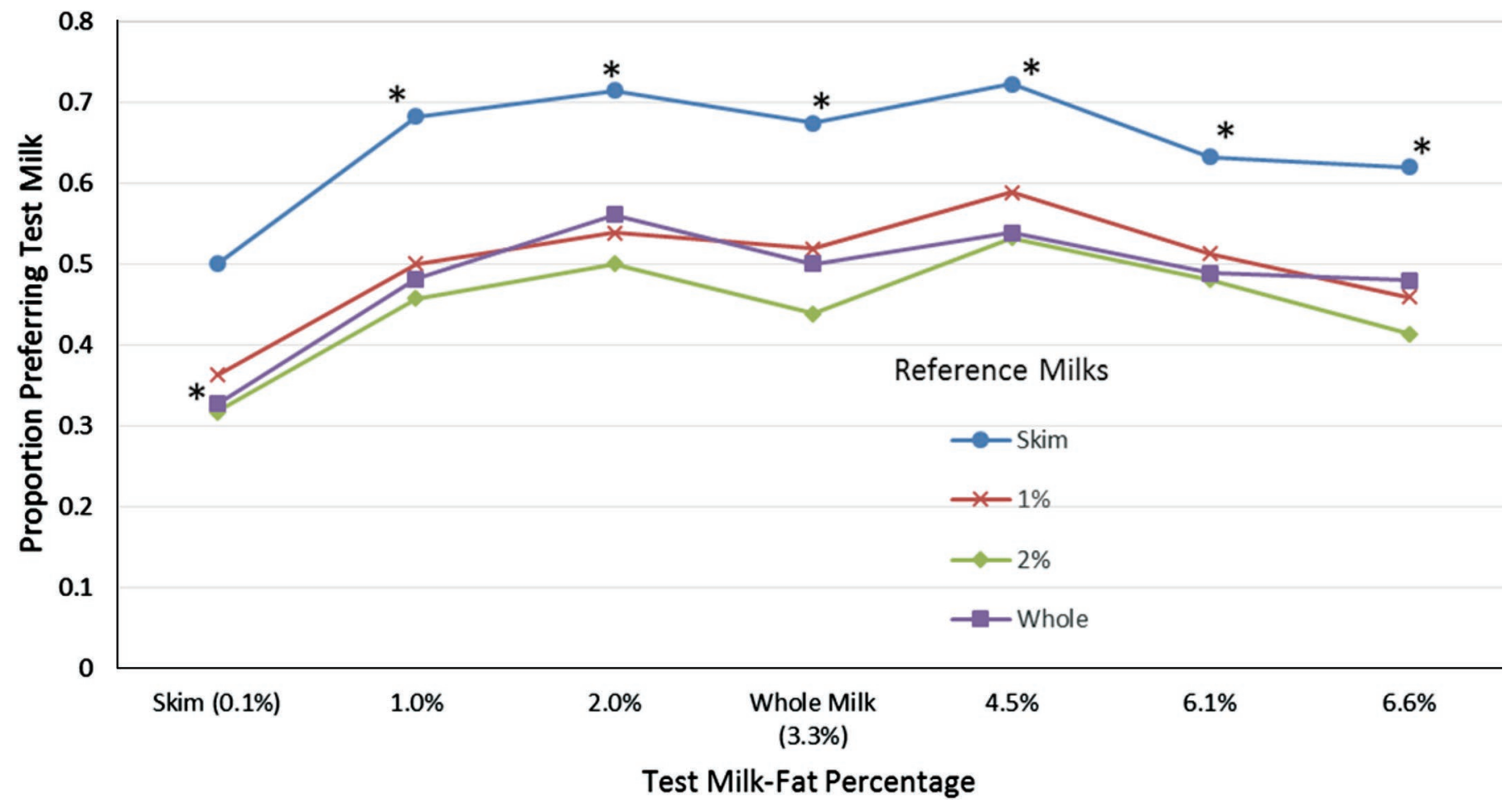

Figure 1. Preference curves from 2 ascending forced-choice preference for milks with different fat contents for all consumers $(\mathrm{n}=172)$. Each line represents the designated reference milk in the pair; an asterisk $\left.*^{*}\right)$ indicates significance $(P<0.05)$. Color version available online. 


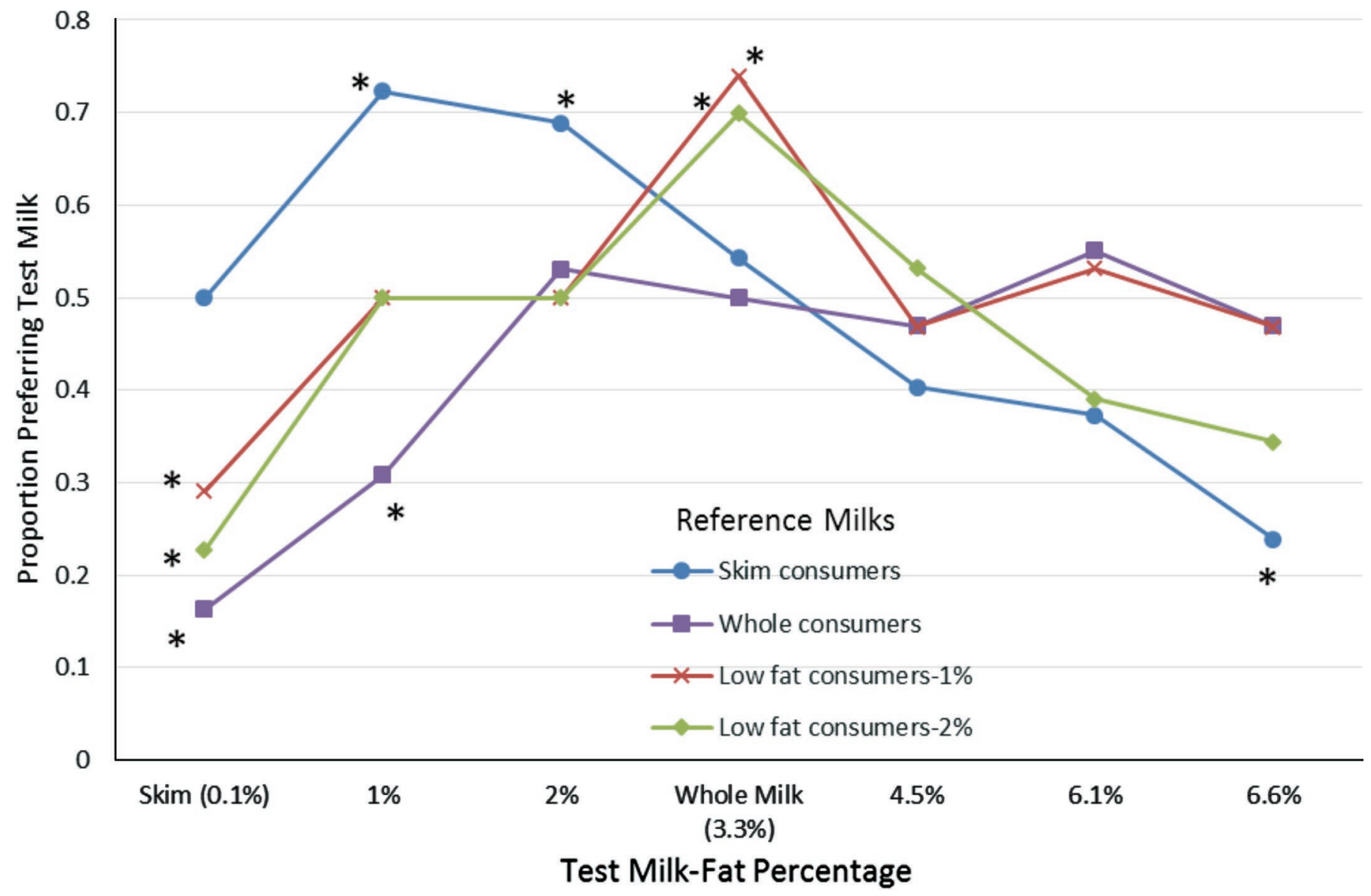

Figure 2. Preference curves for milks for each self-reported milk consumer group. Each line represents the preference for that consumer group for the test milk when their self-reported usually consumed milk was the reference milk: skim milk drinkers $(\mathrm{n}=59)$, low-fat milk drinkers $(\mathrm{n}=$ $64)$, whole milk drinkers $(\mathrm{n}=49)$. Low-fat milk drinker results were presented with $1 \%$ and $2 \%$ fat milk as the reference milk. An asterisk $(*)$ indicates significance $(P<0.05)$. Color version available online.

milks across milk fat JND thresholds. No other previous studies have determined milk fat thresholds and then separated skim, low-fat, and whole milk drinkers and tested paired preferences for blinded samples with the only variable of milk fat. This research bridges that gap, where skim milk drinkers are separated from lowfat consumers or all milk consumers, and establishes that skim milk drinkers prefer some milk fat but have a different milk fat preference level than that of consumers who typically drink low-fat or whole milk.

\section{Preference Follow-Up Interviews}

Qualitative interview results provided further clarification of consumer segment preferences. When skim milk drinkers were presented with skim and $2 \%$ milk samples, $2 \%$ milk was selected and consumers stated that the reason for preference was "like the thickness," "stronger flavor," "better aftertaste," "less watery," "fuller flavor," and "better color." They were then given $2 \%$ milk and whole milk. The $2 \%$ milk was preferred and consumers stated that the whole milk was "too creamy," "had too much aftertaste," and "had more of a filmy residue." When skim milk drinkers were then presented with skim milk and $6.6 \%$ fat milk, preference went back to skim milk. Skim milk consumers stated that the $6.6 \%$ milk was "too thick," "too heavy," "flavor and texture like cream," "too fatty," and "looks like half and half." Skim milk drinkers preferred some milk fat in their milk but disliked milk when it continued to increase in milk fat and they felt it was too creamy, too thick, and too heavy.

Low-fat milk drinkers were asked to first evaluate skim milk and $2 \%$ milk. The $2 \%$ milk was selected with reasoning being the skim milk was "too watery" and the $2 \%$ was "richer," "creamier," "tasted more like milk," and "had a better aftertaste." When they were given $2 \%$ and whole milk, whole milk was preferred because 
they "preferred the color/whiteness," thought it was "creamier," and because it tasted "richer." The third pair presented was $2 \%$ and $6.6 \%$ milk. The $2 \%$ milk was preferred because it was "less thick," had no "residue" left on the sides of the cup, and because the $6.6 \%$ milk was "too rich." Low-fat milk drinkers followed a similar trend as skim milk drinkers; they preferred slightly more fat in their milk than they normally consumed but disliked milk when they felt it too rich and too thick.

Skim milk and low-fat milk drinkers both stated aftertaste as a deciding factor in preferences for milk. Porubcan and Vickers (2005) characterized milk aftertaste and consumer acceptability within those who dislike milk. Focus group results suggested that milk aftertaste was a driver of dislike. A trained panel determined sour taste, dairy sour, fatty mouth coating, and lingering dry mouthcoat were the milk aftertaste attributes described by focus group participants. Consumers stated milk aftertaste was a definitive component as to why they did not like dairy milk. Francis et al. (2005) determined that milk fat had a critical role in the aftertastes of fresh milk. Results showed that lower-milk fat samples had higher maximum intensities and persistence of cooked flavors in the aftertaste at 15 and $90 \mathrm{~s}$. Higher-milk-fat samples had higher maximum intensities and persistence of sweet and sweet-related attributes in the aftertaste. In the current study, the aftertaste of skim milk was not preferred or liked by skim milk or low-fat milk consumers.

When whole milk drinkers were interviewed, they showed a preference toward milk fat and the attributes it contributes to fluid milk. Whole milk drinkers were presented with skim and whole milk and selected whole milk because they liked the "thickness," "color," and thought the whole milk had "more flavor." They then evaluated whole milk and $6.6 \%$ milk, showing a preference the $6.6 \%$ milk and stating it was "creamier," had a "fuller flavor," "tasted richer," and that it had "more body/mouthfeel."

These qualitative results give insights as to why each consumer segment had distinct preferences for milks. Skim milk drinkers preferred up to $2 \%$ milk but did not like the aftertaste of skim or the flavor and texture of the $6.6 \%$ milk, milk fat content far above what they normally consume. Low-fat milk drinkers disliked skim milk for its appearance, aftertaste, and perceived watery flavor but also did not like the $6.6 \%$ milk because they felt it was too rich in flavor and did not like the texture. Whole milk drinkers preferred whole milk over skim due to flavor, texture, and appearance and then preferred $6.6 \%$ milk over whole due to a richer flavor and texture. Collectively these results confirm that milk fat provides appearance, flavor, mouthfeel, and aftertaste attributes to fluid milk that are desired by consumers at varying intensities. All consumers preferred some level of milk fat over skim, and preference was not solely due to the appearance of skim. It should be noted that our study was conducted in a very controlled environment to ensure milk fat was the only factor affecting the fluid milk. Other factors may also affect consumer liking, such as the flavor heat treatment imparts, possible undesirable flavors from vitamin fortification, or light oxidation. In addition, previous literature concluded consumers drink certain milks due to sensory properties but also beliefs and health concerns (Brewer et al., 1999).

\section{Descriptive Analysis}

Significant differences were noted among all milks in milk fat or lactone flavor, viscosity, and yellow color $(P$ $<0.05$; Table 4). Milk fat or lactone flavor, viscosity, and yellow color increased as fat content increased in the milks. Opacity increased as astringency decreased with fat content $(P<0.05)$. Sweet taste and sweet aromatic flavor followed the same trend, but cooked flavor was not different between the milks and aroma intensity was only lower in the skim milk $(P<0.05$; Table 3). These results align with previous literature on the effect of milk fat and milk appearance, flavor, and texture of milk (Phillips et al., 1995; Francis et al., 2005). Greater differentiation in flavor attributes was documented in the current study compared with previous work, perhaps due to more panel training or more specifically defined flavor lexicon terms for milk than previous studies. The current study trained panel results also quantify the differences that the consumers described in appearance, flavor, and texture of each pair they evaluated. Consumers frequently stated that skim milk was more watery, which is reflected in the trained panel opacity and viscosity scores. Consumers also stated that milk flavor or milk fat was a reason they preferred or did not prefer the higher-fat sample. The trained panel was able to distinguish that the higher-fat milks did have high milk fat flavor and viscosity. Thickness was also an attribute that drove preference of high-fat milks for whole milk drinkers and lower-fat milks for skim and low-fat drinkers. It is worth noting that milks with a higher percentage of milk fats were mentioned by consumers to have thicker mouthfeel, stronger (more intense) flavor, different color, and to be "creamier" and "richer," and these perceptions were confirmed by trained panelists in descriptive analysis. However, there seemed to be an optimum level for these attributes in term of overall preference for consum- 
Table 4. Descriptive analysis of milks used in follow-up interviews, a subset from the milks used in the preference testing ${ }^{1}$

\begin{tabular}{lcccc}
\hline Item & $\begin{array}{c}\text { Skim milk } \\
(0.1 \%)\end{array}$ & $\begin{array}{c}2 \% \\
\text { milk }\end{array}$ & $\begin{array}{c}\text { Whole milk } \\
(3.25 \%)\end{array}$ & $\begin{array}{c}6.6 \% \\
\text { milk }\end{array}$ \\
\hline Aroma intensity & $2.0^{\mathrm{b}}$ & $2.2^{\mathrm{a}}$ & $2.3^{\mathrm{a}}$ & $2.3^{\mathrm{a}}$ \\
Sweet aromatic & $1.6^{\mathrm{c}}$ & $1.9^{\mathrm{b}}$ & $2.0^{\mathrm{ab}}$ & $2.1^{\mathrm{a}}$ \\
Cooked & $2.9^{\mathrm{a}}$ & $2.9^{\mathrm{a}}$ & $2.9^{\mathrm{a}}$ & $2.8^{\mathrm{a}}$ \\
Milk fat/lactone & $\mathrm{ND}^{2}$ & $1.6^{\mathrm{c}}$ & $2.9^{\mathrm{b}}$ & $3.7^{\mathrm{a}}$ \\
Sweet taste & $1.8^{\mathrm{b}}$ & $1.9^{\mathrm{ab}}$ & $2.0^{\mathrm{a}}$ & $2.0^{\mathrm{a}}$ \\
Astringency & $1.8^{\mathrm{a}}$ & $1.5^{\mathrm{b}}$ & $1.4^{\mathrm{b}}$ & $1.1^{\mathrm{c}}$ \\
Viscosity & $1.3^{\mathrm{d}}$ & $1.6^{\mathrm{c}}$ & $1.8^{\mathrm{b}}$ & $2.4^{\mathrm{a}}$ \\
Opacity & $8.1^{\mathrm{c}}$ & $11.0^{\mathrm{b}}$ & $12.1^{\mathrm{a}}$ & $12.6^{\mathrm{a}}$ \\
Yellow color & $0.7^{\mathrm{d}}$ & $2.0^{\mathrm{c}}$ & $2.5^{\mathrm{b}}$ & $3.7^{\mathrm{a}}$ \\
\hline
\end{tabular}

$\overline{\mathrm{a}-\mathrm{d}}$ Different letters in rows following means represent significant differences $(P<0.05)$.

${ }^{1}$ Attribute intensities were scored on a 0 to 15 point universal intensity scale (Meilgaard et al., 2007).

${ }^{2} \mathrm{ND}=$ not detected

ers who were familiar with different levels of milk fat (skim, low-, and full-fat milks). Data published by the USDA has demonstrated that $1 \%$ and $2 \%$ fat milks have increased in sales in the past years. The dairy industry should take advantage of this trend, as $1 \%$ and $2 \%$ milks meet in the middle between all consumers providing the positive sensory attributes of milk fat and the perceived health benefits that consumers' value.

\section{CONCLUSIONS}

Skim milk drinkers preferred $1 \%$ and $2 \%$ milks and stated they preferred $2 \%$ milk over skim in interviews due to appearance, flavor, and thickness. Our JND results show that skim milk at $0.5 \%$ fat was visually different from skim milk at $0.1 \%$ fat. Therefore, skim milk at $0.5 \%$ fat remains within the legal definition of skim milk but may be more appealing to skim milk consumers because of the visible difference and potentially a perceived creamier taste due to appearance. Low-fat milk drinkers preferred $2 \%$ and whole milk in the paired preference tests. In interviews, they preferred whole milk over $2 \%$ because of the appearance, richness in flavor, and perceived creaminess. Because of the legal restriction of milk fat in $1 \%$ or $2 \%$ milk, the addition of skim milk powder might enhance appearance and perceived creaminess to consumers. Milk fat is preferred by all consumer segments to varying levels. After drinking a certain fat percentage of milk for an extended amount of time, consumers prefer milk with similar sensory properties, creating different preference groups. It is also possible that biological differences are the reason behind differential consumption and liking for fat in milk. This study identified the sensory profiles and the level of milk fat preferred by skim, low-fat, and whole milk drinkers that can also guide the development of new dairy beverages that can fulfill consumer flavor and mouthfeel desires.

\section{ACKNOWLEDGMENTS}

Funding was provided in part by the National Dairy Council (NDC, Rosemont, IL). The use of trade names does not imply endorsement or lack of endorsement by those not mentioned.

\section{REFERENCES}

Allen, G. A. 1981. The x2 statistic and Weber's law. Teach. Psychol. 8:179-180.

AOAC International. 1992. Fat in Milk-Modified Mojonnier Ether Extract. 989.05. Official Methods of Analysis. AOAC International, Gaithersburg, MD.

ASTM. 2011. Standard Practice for Determination of Odor and Taste Thresholds by a Forced-Choice Ascending Concentration Series Method of Limits. E679-04. American Society for Testing and Materials, Philadelphia, PA.

Bakke, A. J., C. V. Shehan, and J. E. Hayes. 2016. Type of milk typically consumed and stated preference but not health consciousness affect revealed preferences for fat in milk. Food Qual. Prefer. 49:92-99.

Brewer, J. L., A. J. Blake, S. A. Rankin, and L. W. Douglass. 1999. Theory of reasoned action predicts milk consumption in women. J. Am. Diet. Assoc. 99:39-44.

Croissant, A. E., S. P. Washburn, L. L. Dean, and M. A. Drake. 2007. Chemical properties and consumer perception of fluid milk from conventional and pasture-based production systems. J. Dairy Sci. 90:4942-4953.

Drake, M. A., Y. Karagul-yuceer, K. R. Cadwallader, G. V. Civille, and P. S. Tong. 2003. Determination of the sensory attributes of dried milk powders and dairy ingredients. J. Sens. Stud. 3:199-213.

Drake, S. L., K. Lopetcharat, and M. A. Drake. 2011. Salty taste in dairy foods: Can we reduce the salt? J. Dairy Sci. 94:636-645.

Drake, M. A., M. D. Yates, and P. D. Gerard. 2005. Impact of serving temperature on trained panel perception of Cheddar cheese flavor attributes. J. Sens. Stud. 20:147-155.

Economic Research Service. 2014. Data files: Dairy Products: Per capita consumption, United States (Annually). Accessed June 8, 2014 http://www.ams.usda.gov/AMSv1.0/ams.fetchTemplateData.do? startIndex $=1 \&$ template $=$ TemplateV \&navID=IndustryMarketing andPromotion\&leftNav $=$ IndustryMarketingandPromotion\&page $=$ FluidMilkSalesDataMonthlyandYeartoDate\&acct $=$ dmktord.

Francis, L. L., D. H. Chambers, S. H. Kong, G. A. Milliken, I. J. Jeon, and K. A. Schmidt. 2005. Serving temperature effects on milk flavor, milk aftertaste, and volatile compound quantification in nonfat and whole milk. J. Food Sci. 70:S413-S418. 
Gould, B. W., T. L. Cox, and F. Perali. 1990. The demand for fluid milk products in the U.S.A.: Demand systems approach. West. J. Agric. Econ. 15:1-12.

Jervis, S. M., P. Gerard, S. Drake, K. Lopetcharat, and M. A. Drake. 2014. The perception of creaminess in sour cream. J. Sens. Stud. 29:248-257.

Meilgaard, M., G. V. Civille, and B. T. Carr. 2007. Descriptive analysis techniques, Chapter 10 in Sensory Evaluation Techniques, 4th ed. CRC Press, Boca Raton, FL.

Palacios, O. M., J. Badran, M. A. Drake, M. Reisner, and H. R. Moskowitz. 2009. Consumer acceptance of cow's milk versus soy beverages: impact of ethnicity, lactose tolerance and sensory preference segmentation. J. Sens. Stud. 24:731-748.

Phillips, L. G., M. L. McGiff, D. M. Barbano, and H. T. Lawless. 1995. The influence of fat on the sensory properties, viscosity, and color, of lowfat milk. J. Dairy Sci. 78:1258-1266.

Porubcan, A. R., and Z. M. Vickers. 2005. Characterizing milk aftertaste: The effects of salivation rate, PROP taster status, or small changes in acidity, fat, or sucrose on acceptability of milk to milk dislikers. Food Qual. Prefer. 16:608-620.

Quiñones, H. J., D. M. Barbano, and L. G. Phillips. 1997. Influence of protein standardization by ultrafiltration on viscosity, color, and sensory properties of skim and 1\% milk. J. Dairy Sci. 80:31423151.

Richardson-Harman, N. J., R. Stevens, S. Walker, J. Gamble, M. Miller, and A. McPherson. 2000. Mapping consumer perceptions of creaminess and liking for liquid dairy products. Food Qual. Prefer. $11: 239-246$.

Saba, A., E. Moneta, N. Nardo, and F. Sinesio. 1998. Attitudes, habit, sensory, and liking expectation as determinants of the consumption of milk. Food Qual. Prefer. 9:31-41.

Smeets, J. B. J., and E. Brenner. 2008. Grasping Weber's law. Curr. Biol. 18:R1089-R1090.

Tamsma, A., F. E. Kurtz, R. S. Bright, and M. J. Pallansch. 1969. Contribution of milk fat to the flavor of milk. J. Dairy Sci. 52:1910-1913.

Tepper, B. J., and T. Kuang. 1996. Perception of fat in a milk model system using multidimensional scaling. J. Sens. Stud. 11:175-190.

Tuorila, H. 1987. Selection of milks with varying fat contents and related overall liking, attitudes, norms, and intentions. Appetite $8: 1-14$. 